\title{
Influence of Parental Education on Career Development of Youths with Intellectual Disabilities in Selected Skills Training Institutions in Zambia
}

\author{
Mathatha Viola $^{1^{*}}$, Ndhlovu Daniel $^{2}$ \\ Zambia
}

*Corresponding Author: Mathatha Viola, Zambia

\begin{abstract}
This paper discusses the influence of parental education on career development of youths with intellectual disabilities (IDs) in selected skills training institutions in Zambia. The phenomenological study was carried out in Kabwe, Chisamba and Ndola districts of Central and Copperbelt Provinces respectively. Purposive sampling was to select a sample of 60 respondents: parents of youths with IDs (30), youths with IDs (15) and lecturers of youths with IDs (15).Semi-structured interviews, observations and Focus Group Discussions were used to collect data. Data analysis was done thematically. The study revealed that parental education influences career development of youths with intellectual disabilities through encouragements, explanations, warning and advice. Based on the findings, the study recommends that the government through the Ministry of Higher Education should sensitize parents of children with IDs on their important role as primary educators and facilitators of their children's career development.
\end{abstract}

Keywords: Career Development, Intellectual Disability, Parent, Education

\section{INTRODUCTION}

Preparation youths for future life roles in the world of work has become increasingly important for educators. For youths with intellectual disabilities, the challenge is to prepare them to enter the world of work and compete with those without disabilities. It follows therefore that to be prepared for the world of work, career development must be a priority especially for those with IDs. Equally, parents often wonder what their children will do when they are grown up. According to Kerka (2000), parents are one of the most important and influential elements in preparing their children for future lives. However, they may not be aware of their influence. Research has shown that parents have the power and ability to shape, sustain and develop their children's career development through their positive involvement in educational activities of their children (Ceka\&Murati, 2016).

In home settings, the learning processes occur explicitly or consciously, often in an informal way. Parents teach and train their children early in their lives the fundamental skills, attitudes and values necessary for day-to-day living (Farrant, 2011). The unwritten knowledge being conveyed by parents to their children, is specific and to a certain degree, specialized. Parents target issues that would enable their children to cope successfully with the requirements of the immediate confines of homes and the community. What is of concern is how parental education influences career development of youths with IDs.

\subsection{Statement of the Problem}

While research has shown that parental education is positively related to career development of youths (Whiston\& Keller, 2008; Munyingi 2012; Udo \&Sanni, 2012), how parental education influences career development of youths with intellectual disabilities is still unknown. Neglecting such an area can worsen the already existing high unemployment rates among youths with intellectual disabilities.

\subsection{Purpose}

The purpose was to establish the influence of parental education on career development of youths with IDs in selected skills training institutions in Zambia. 
Influence of Parental Education on Career Development of Youths with Intellectual Disabilities in Selected Skills Training Institutions in Zambia

\subsection{Research Objectives}

- To determine how parental education influences career development of youths with IDs.

\subsection{Research Questions}

- How does parental education influence career development of youths with IDs?

\subsection{Theoretical Framework Theoretical Framework}

The Ecological Systems Theory by UrieBronfenbrenner (1999) guided the study. The theory believes that development is best understood by examining ones' context. It states that career development depends on the heterogeneity of individuals and is influenced by the context in which they live. The theory believes that a person's ability to reach their potential is dependent on the presence of real life opportunities in the environment (Roundy, 2015). It argues that individuals better adjust and are more satisfied in environments that match their attitudes, values, goals and experiences, that is, they are more satisfied when there is a fit between themselves and their environment (Schutheiss, Kress, Manzi\& Glasscock, 2001). Being congruent with one's parents on career matters reflects a fit which is likely to foster career development (Duffy \&Dik, 2009). Incongruity or lack of fit on the other hand is a potential external barrier to career development (Schutheiss, et al., 2001). The theory states that parents influence development of their children through their interactions, relationships and expectations (Duffy \&Dik, 2009). The more encouraging and nurturing the environments are, the better the child will be able to develop.

\subsection{Significance of the Study}

Findings may contribute to the knowledge gap on the significant influence of parental education oncareer development of youths with IDs.

\section{LiTERATURE REVIEW}

Faisal (2014) investigated the relationship between parental SES strategies on their children's education among Jordanian parents who had enrolled their children in government schools. The total sample of 150 Jordanian students who completed their (Tawjechi) education government school was used. Purposive convenient sampling was used to select the sample. Questionnaires were used to collect data related to parental SES, background and their involvement in their children's education from selected parents. Results indicated that the level of education has greater impact on parental involvement strategies in education. The study recommends that family care agencies and interventions are important to parental involvement and their role in helping their children to have better education. It is not known how parental education influences career development of youths with IDs in Zambia.

Munyingi (2012) conducted a study using cross sectional research design on the factors that influence career choices among young females in tertiary institutions in Kenya. The study revealed that educational levels of parents positively influenced aspirations of female youths. Much as Kenya could have similar conditions as Zambia, the study was done on females without disabilities only. The current study has a focus on the influence of parental education on career development of youths with IDs (both males and females) using a phenomenological study design.

A study was undertaken by Pappas and Kounenou (2011) to determine the impact of both parents and career decision making self-efficacy on Greek post-secondary vocational students' career decision making. Among variables investigated was parental education background. The students career decision self-efficacy was measured using the Career Decision Self-Efficacy-Short Form scale (CDSE-SF) developed by Betz, Klein and Taylor (1996). Parental influence was measured by using a Career Decision Making Questionnaire developed by the researchers. Instruments were administered to148 students (58 females and 90 males). The results of the study indicated significant correlation between students' Career Decision Self-efficacy and career decision making, with respect to the educational level of the mother. Results also revealed a strong correlation between parental influence and career decision making ability. However, this study was conducted in Greece on students without disabilities and using the CDSE-SF. This leaves cause to wonder whether the use of interviews, observations and FGDs on parents of youths with IDs, their children and lecturers of such children would yield similar results in the Zambian context. 
Eccles (2009) looked at influence of parental education on children's educational attainment focusing on the role of parents and child perceptions in Michigan, USA. The study used variables such as parental income, parental occupation and residence. The review showed a relationship between parental education and children's academic achievement.

Lusk and Fazarro (2006) conducted a study using a correlational research design on parents as a limiting factor in career development of learners with disabilities in the United States of America. The study found that parental factors such as low educational and occupational status, attitudes and personal biases towards their own occupations and others' occupation(s), financial concerns, rules and expectations affected career development of learners. The study was conducted in the USA using a correlational design. This raises concern as to whether a phenomenological study on the influence of parental education on youths with IDs in Zambia would yield similar results. There is also need to know how parental education influences career development of youth with IDs.

A key study by Davis-Kean (2005) focused on the extent to which parental level of education impacts on their beliefs and behaviours in the home and the expectations they hold for their children. This study's findings also relate levels of parental education to the way in which they interact with their children and promote academic achievement. The study found that home activities that encourage academic competence such as homework monitoring, assistance with school work or going to science museums or libraries have stronger relations with achievement and career development. This study however, was conducted in the USA and on children without disabilities 12 years ago. It leaves the researcher with a question of how parental education influences career development on youths with IDs in the African context.

Whiston and Keller's (2004) survey in Latin America on the influence of the family found that parental education influenced what the child learnt about work and work experiences. In addition to this, parental education reflected parental attitudes about school and work, which in turn had a longterm impact on their young adolescents' career choices, decisions and plans. The study however, was conducted in Latin America and used a survey method as opposed to a phenomenological approach in the current study. The researcher wonders how parental education influences career development of youths with IDs in the Zambian context.

A study was conducted in the 1980's examining the family influence on the career aspirations of girls. The study examined the question of girls aspiring to careers that could be viewed as a higher level and traditionally dominated by males (Sandberg, Ehrhardt, Mellins, Ince, \& Meyer-Bahlburg, 1987). Findings indicated that the chief factor in adolescence predicting girls becoming pioneers was the correlation with parental higher education. To a smaller degree femininity tended to be emphasized less for these pioneer girls during their childhood and adolescence and these girls more frequently had mothers who had worked outside the home when growing up. This perhaps provided a role model (even if in a more traditionally female occupation) for the pioneer girl. Therefore, although one would need to concede that there are few absolute predictors, at least a higher level of parental education and the mother working outside the home are correlated with girls seeking occupations traditionally filled by men. As with any research performed regarding gender roles more than 15 or 20 years ago, it raises curiosity on whether or not a study on influences of parental education on career development would yield similar results today with youths (both males and females) with IDs in Africa.

\section{Methodology}

\subsection{Research Design}

The study used the phenomenological study design (Astalin, 2013) to examine lived experiences through the description provided by the people involved or involved in the issue that being researched (Creswell, 2014). The design was selected because it is best used in examining lived experiences, is normally used where there is little knowledge on a phenomenon (Donalek, 2004) and the study relied more on qualitative methods.

\subsection{Research Sites}

The study was conducted at Chipembi Farm College, Chisambain Central Province, Kabwe School for Continuing Education, Kabwe in Central Province and the National Vocational Rehabilitation 
Centre, Ndola on the Copperbelt Province where youths with IDs from across the country are offered skills training.

\subsection{Target Population, Sample Size and Sampling Procedure}

The population consisted of all youths with IDs at the named sites, their lecturers and their parents. The sample comprised sixty (60) purposively selected respondents; thirty (30) parents of with IDs, fifteen (15) youths with IDs and fifteen (15) lecturers of youths with IDs.

\subsection{Research Instruments, Data Collection Procedures and Data Analysis}

The study used semi-structured interviews, observations and Focus Group Discussions (FGD) to collect lived experiences from respondents. These were deemed appropriate because interpretivist researchers favour to interact and dialogue with the studied participants (Wahyumi, 2012). Semistructured interviews were administered to all respondents. FGDs were conducted to youths only. Observation was employed to assess the self-esteem of youths with IDs. Triangulation was done through documentary study. Data was analyzed thematically.

\subsection{Ethical Considerations}

Consistent with Reinsk (2011), ethical considerations such as seeking permission from the university ethical committee and site authorities, respondent issues of confidentiality and other basic research conventions were taken into account. For youths with IDs, consent was sought from site authorities.

\subsection{Validity}

As a way to validate contents, the report was peer reviewed.

\section{FINDINGS AND DISCUSSION}

\subsection{How Parental Education Influences Career Development of Youths with Intellectual Disabilities.}

The study revealed that parental education influences career development of youths with IDs through encouraging youths with IDs to work hard at school, explaining the importance of education, advising youths on the need to work hard and through warnings.

\subsubsection{Through Encouraging Youths to Work Hard at School}

The study revealed that parental education influences career development of youths with IDs, through encouraging youths to work hard at school.

Balalanda ati ndeposako amino ku sukulu... (They tell me to work hard at school...) (Y6,

Female, 19, General Agriculture).

Consistently studies like those of Liu et al., (2015); Halim, et al., (2017) found that parents who encouraged their children fostered better academic work, positive school attitudes and higher aspirations. These similarities show that the progress that some youths with IDs could have made resulted from encouragements they received from their parents. For parents of youths with IDs, this encouragement was obviously anchored on the dominant ideology that education is critical for upward social mobility (Carter \&Readan, 2014), educational achievement, societal participation and overall human wellbeing. The encouragement was also possibly as a result of parents of youths with IDs' innate responsibility to ensure they prepare their children for the future.

Recent studies have shown that educated parents have high educational expectations for their children (Latashia, 2012; Duristic \& Bunijevac, 2017) which in turn drive them to engage in talks with their children on life goals and steps to get there. Parental aspirations affect children's behaviour, which in turn, affects children's beliefs about their own abilities, which in turn affect children's involvement in school activities (Eccles, 2009). Education also influences parental beliefs and behaviours which in turn, influence children's skills, values concepts motivation, which in turn influence the children's engagement in the variety of activities at home. Considering that youths in this study have IDs, it is obvious that the operating message behind parental encouragements could have been, "I want you to show that you are able." This result could mean that such parents understood ID. It could also mean that such parents still believed in their children regardless of the ID. This means educated parents of 
Influence of Parental Education on Career Development of Youths with Intellectual Disabilities in Selected Skills Training Institutions in Zambia

youths with IDs had expectations which made them encourage their children work hard thereby developing careers. This reaffirm calls for educators to encourage parents of youths with IDs to constantly engage their children in encouraging interactions.

Sadly though, parental education affects career development of youths with IDs negatively through pressure they exert on their children because of their high expectations.

Ni batate bananileta kuno kuti niphunzile volima.... Namwine wake nenze kufuna kunkhala kapokola (It is my father who brought me here to train in General Agriculture. I wanted to be Police Officer).(Y3, Male, 21, General Agriculture).

Consistently, Tziner et al., (2012) report that some parents control their children's choices too much making children more passive in the process of career development. It is possible that youths with IDs who were pushed into certain careers were frustrated and this negatively obviously affected their career development process. Therefore, it is important that parents of youths with IDs mind the extent to which they express their expectations. For such children, parents should have realistic expectations for their children's educational career development.

Educated parents provide different types of encouragements through acts such as financial support and they look for ways to help their children in preparation for future lives. Similarly, in this study, some parents of youths with IDs sponsored their children. Davies-Kean (2005) notes that educated parents also provide their children's educational experiences at home through monitoring activities and engaging in talks about school. This is because parents with a higher education are likely to have a higher incomes and a higher paying jobs which make them able to support their children's education. Consistently, support, provision of different activities, communications and monitoring youth's activities were encouraging acts that obviously fostered career development of youths with IDs in this study.

On the contrary, studies have shown that parents with low levels of education are likely to have children with lower cognitive development levels (Cole, 2011). It can be deduced that youths with IDs in this study whose parents had low education, had low cognitive development levels because their parents never provided the needed educational experiences and opportunities (Eccles, 2009). This obviously affected career development of youths with IDs negatively. Lack of exploration seemed to be exacerbated by the dearth of interactions. Without the educational opportunities, career aspirations of youths with IDs were constrained. The findings of this study confirm that youths with intellectual disabilities are still limited to a lot of career activities. As such, the extent to which parents are involved in their children's education and in family chores is important.

It can be concluded that parents of youths with IDs who encouraged their children were authoritative. Authoritative parents encourage their children to work hard at school, offer support, motivation and practice conveyed in loving words (Ceka\&Murati, 2016). Whiston and Keller (2004) point out that through encouraging parent-child interactions, working roles are embedded in children's ecological subsystems promoting career development. In this case, as parents of youths with IDs encouraged their children, working roles were embedded in the eco systems of the youths with IDs thereby enhancing career development. This explains why some youths with IDs said they had interest in pursuing their training and work later. Likewise, Elham et al., (2012) showed that parental education is influential when it is characterized by encouraging interactions. This finding suggests that the environment of an individual shapes his or her interests in turn, influencing career development. Therefore, adopting Hans (2012)' thoughts, parents of youths with IDs should begin encouraging talks long before children enter school. Consistently, ecological theory believes that the more encouraging and nurturing the interactions are, the more the children are likely to develop careers (Roundy, 2015).Educators should also equip parents of youths with IDs with appropriate knowledge and skills to foster their children's career development.

According to Rafiq et al., (2013), learning begins at home fostered by encouraging parent-child interactions. As such, in this study, parents of youths with IDs who enriched their children's career activities with stimulating interactions that triggered curiosity and exploration urge enhanced career development. This linked the abstract concept of career development career choices (Whiston\& Keller, 2008). This means that parents of youths with IDs should engage in stimulating interactions 
Influence of Parental Education on Career Development of Youths with Intellectual Disabilities in Selected Skills Training Institutions in Zambia

that would arouse youths' interest and foster their career development especially that they are the first role models.

\subsubsection{Through Advising Youths to Value Education}

A thorough review of the responses indicates that parental education influences career development of youths with IDs through parents advising children to value education.

I talk to her about my education and how it led to what I am doing now... and she knows that I value education... Due to her condition, she might not understand the value of education if I do not help to her.(P8, Female, Tertiary, Formal employment).

Consistently, Latashia (2012) and Zhao et al., (2012) found that parents who were involved in the education of their children advised them on its value. Taken together, these results indicate that children's conception of work begin in the immediate environment (family) through advisory interactions. Although parents' principle role is the education and upbringing of their children, they need to advise children on the value of education to open doors for the world of work (Ceka \& Murati, 2016).Similarly, research by Cole (2011) shows that children normally value what they get from their parents. This is possibly because children always feel that parents know more than anyone else. Likewise, Whiston and Keller (2008) found that young adults sort for advice from their parents more than any other member of the family. Therefore, parents of youths with IDs who engaged in advisory parent-child interactions helped children focus on future adult life. Consistent with the ecological theory, if parents advise their children, they create a fit between the environment and children, fostering career development. Although parental advice may be influential, parents may be unaware of such an influence, hence the need for sensitization.

\subsubsection{Through Warning Youths to be Serious with School}

The study revealed that parental education influence career development of youths with IDs through warning children to be serious with school.

I tell her if she does not work hard at school she will suffer. (P17, Male, Tertiary, Formal employment).

This finding contradicts those of Ceka and Murati (2016), Liu et al., (2015), Rani (2014), Rafiq et al., (2013), Elham et al., (2012), Cole (2011) showed that learning begins from the home environment with encouraging parent-child interactions. This finding indicates that parents of youths with IDs understood that education is critical for upward social mobility (Carter \&Readan, 2014), however, they lacked communication skills.

Although these warnings could have pushed youths with IDs to work hard, they made the environment fearful negatively affecting career development. Possibly, parents of youths with IDs who engaged in warnings were authoritarian. Such a parenting style leads to children with low selfesteem and poor academic performance (Rani, 2014). Hence, the need to help parents of youths with IDs to engage in stimulating interactions with their children (Whiston\& Keller, 2008). All children are born wired for feelings and ready to learn (Shankorf, 2003), however, this can be frustrated by experiences at home. Consistent with the ecological theory, these warnings created a poor fit or incongruity between the youths with IDs and their environment inhibiting career development (Roundy, 2015). Therefore, educators should provide support services for good parenting.

\subsubsection{Through Explaining the Importance of Education}

Findings show that parental education influences career development of youths with IDs through explanations on the importance of education.

Whenever we talk to our child, we explain the importance of education. (P29, Male, Secondary education, Non-formal employment)

This result concurs with that of Elham et al., (2012) hich found that parents explained the need for their children to be educated to be successful adults. Explanations give children a sense of their parents' principles, desires and goals that are associated with later life (ibid).Through explanations, parents of youths with IDs influenced employability skills, inculcated life roles and values their children subsequently adopted. 
Influence of Parental Education on Career Development of Youths with Intellectual Disabilities in Selected Skills Training Institutions in Zambia

My mother says that I should work hard at school so that when I finish, I should start working and help my siblings. (Y10, Female, 22, Food Production).

Similarly, Elhalm et al., (2012) found that parents encouraged their children to work hard for the sustenance of the family. Hence, explanations helped the youths to map their career paths through exploring their talents, desires and aspirations. With encouragements, youths with IDs obviously had better performance in school. Concurrently, the ecological theory believes that parents influence their offspring's occupational knowledge, values, career exploration, career aspiration and career efficacy through explanations (Whiston\& Keller, 2004).It can be deduced that parents of youths with IDs who engaged in explanations were authoritative. Authoritative parents love to explain the reasons for each action made (Rani (2014). These explanations helped youths with IDs understand how education leads to better employment and better futures. Similarly, Elham et al., (2012) found that learners who directly received explanatory talks from adults on the importance of education developed careers, understood the world of work, the responsibility of workers and became aware of employment opportunities available. Thus, parents of youths with IDs need to be equipped with appropriate knowledge and skillsto help their children (Bendtro, 2010).Likewise, Bronfenbrenner's theory states that mutual parent-child interactions are predictors of career development (Fulcher, 2011). This is more important since youths with IDs depend on their parents for almost everything (Nord, 2012).

On the contrary, the study also revealed that parental education does not influence career development of youths with IDs.

The education level of parents does not matter at all, what matters is knowing what the child with IDs can do and help them in that way for them to develop careers. (L12, Female, Diploma).

This finding contradicts that of Munyingi (2012) and Liu et al., (2015) who found that parental education influenced career choices of adolescents. This finding indicates how parents of youths with IDs are at risk of information needed for child development (Fulcher, 2011). Since some parents of youths with IDs had primary education, obviously affecting the intellectual environment. Hans (2012) argues that the intellectual environment at home has an impact on the achievement of the developing child and is determined by parents' value of education. Worse still, parents of limited education levels tend to be less capable of engaging or encouraging their children in learning activities (Rafiq et al., (2013); Cole (2011); Duristic and Bunijevac (2017).Although literature on Bronfenbrenner's micro systems acknowledges the importance of teachers on children's career development (Bayraktar, 2011), there is need to explore teachers' educational level and their understanding to help furnish parents of youths with IDs with correct information.

From encouragements, advices, warnings and explanations, youths with IDs got feedback from their parents either verbally or non-verbally. Likewise, Olaosebikan and Olusakin (2014) found that parents convey their career influence to their children not only through both verbal and nonverbal interactions. Hence, the attitudes and behaviours of parents of youths with IDs while interacting is what youths responded to and learnt. If pleasurable or encouraging, their desires to work later in life also grew. Therefore, parents of youths with IDs need to be aware of the communicative power of their gestures as they relate with their children.

It was noted that interactions were not done by most parents. Contrary to Antara's (2016) findings, parents engaged in career conversations with their children thereby influencing career development. Possibly parents of youths with IDs felt obliged during interviews to indicate that they talked to their children just to show that they were responsible. Consistently, Taylor et al., s' (2004) found that parents overwhelmingly ranked themselves as the most influential people in the career development of their children. This implies that these youths neither got feedback from the environment nor were stimulated to work hard. The lack of interactions could have been as a result of low expectations. As pointed out by Bendtro (2010), the discovery of a disability in a child is not only stressful to parents, but it also leads to low expectations. This led to incongruity or poor fit thereby hindering career development. Hence, such parents need to be helped to come into terms with the disability for them to prepare their children for adult life. In addition, the absence of interactions obviously resulted in youths with IDs feeling isolated. According to Bendtro, (2010), loneliness and social isolation has negative consequences on child development. 
While parental education makes parents knowledgeable, the cultural beliefs about disability determine the way the parents perceive, reacts to and the kind of measures they take on disability (Bendtro, 2010). Hence, the need for educators to understand family cultural backgrounds in order to help parents come into terms with IDs and create home environments which promote career development. The extent to which parents are able to create home environments that encourages learning is vital. An ideal environment helps a child to learn skills, attitudes and behaviour which could mold them into productive and successful persons. This finding also reaffirms calls to educate parents of youths with IDs on attitude change towards intellectual disability if they are to help their children develop careers.

\section{CONCLUSION}

The study has shown that parental education influences career development of youths with IDs through encouraging them to work hard at school, advising them to value education, explaining the importance of education and warning them on the need to be serious with school. Although parental education was found to be influential, on career development of youths with intellectual disabilities, it is not known how much education or type of education is needed to gain substantial career development of youths with IDs. This is the challenge that needs to be addressed if we are to adequately assess the extent to which education levels influence career development of youths with intellectual disabilities.

\section{RECOMMENDATION}

Based on the findings, the study recommends that the government through the Ministry of Higher Education should sensitize parents of youths with IDs of their important role as primary educators and facilitators of their children's career development.

\section{REFERENCES}

[1] Astalin, P. K. (2013). Qualitative research designs. A conceptual framework. International Journal of Social Sciences and Interdisciplinary Research. USSIR, Vol 2 (1).

[2] Bayraktar, A. (2011). Possible effects of gender on teacher-student interactions. Procedia Social Behavioural Sciences, 15, 2545-2548.

[3] Bendtro, L. (2010). The vision of Brofenbrenner. http://wwwcyc-netorg/cyc-online/cycloneline-nov2010Bendtro.html.

[4] Bronfenbrenner, U. (1999). Ecology of the family as a context for human development. Research perspectives. Developmental Psychology, 22, 723-742.

[5] Carter, P. L. \& Rearden, S. F. (2014). Inequality matters. William, T. Grant Foundation inequality paper. William Foundation: Staford University.

[6] Ceka, A. \&Murati, R. (2016). The role of parents in the education of children. Journal of Education and practice, Vol 7, (5). 61-64.

[7] Central Statistics Office (2012). 2010 Census of population and housing. National Analytical Report Vol 11. Lusaka: CSO.

[8] Cole, J. (2011). A Research Review: The importance of families and home environment. National Literacy Trust; Angelica Bona.

[9] Creswell, J. (2014). Research design: Qualitative, quantitative and mixed methods approaches. Lincoln: Sage Publishers.

[10] Davies-Kean, P. E. (2005). The influence of parental expectations and family income on child achievement: The indirect role of parent expectations and the home environment. Journal of Family Psychology, Vol 19, (2), 294-304.

[11] Donalek, J. G. (2004). Phenomenology as a qualitative research method. Urologic Nursing. Vol 24, (6), 516-517.

[12] Duffy, R. D. \&Dik, B. J. (2009). Beyond the self- external influences in the career development process. Career Development Quarterly, 58, 29-43.

[13] Durisic, M. \&Bunijevac, M. (2017). Parental involvement as an important factor for successful education. GEPS Journal 7, (3), 137-153

[14] Eccles, J. (2009). Influence of parent's education on their children's educational attainment: The role of parents and child perceptions. London Review of Education, 3, 3, 191-204.

[15] Elham, D. Siti, N.Y., Rumaya, B. J. \&Mansor, A.T. (2012). Relationship between parenting styles and academic achievement in Sirjan. Malaysia. 
Influence of Parental Education on Career Development of Youths with Intellectual Disabilities in Selected Skills Training Institutions in Zambia

[16] Faisal, I.M.A. (2014). The influence of parent social economic status on their involvement at home. International Journal of Humanities and Social Sciences.

[17] Fulcher, M. (2011). Individual differences in children's occupational aspirations as a function of parental traditionality. Sex roles, 64, 117-131.

[18] Hans, C. L. (2012). Parental involvement. Starting Strong III.Parris: OECD.

[19] Keller, B. K. (2004). Parental behaviours that influence adolescent' career development. USA: University of Washington.

[20] Kerka, S. (2000). Parenting and Career Development. Erick Digest No: 214.

[21] Whiston, S. C. (2008). The role of parental influences on young adolescents' career development. Journal of Career Assessment, 16, 198-217.

[22] Latashia, L. J. (2012). The impact of the family influence and involvement on career development. University of Central Florida. Orlando: Florida.

[23] Literacy Policy (2006). Rochdale: Rochdale Council.

[24] Liu, J. MacMahon, M. \& Watson, M. (2015). Parent influence on child development in mainland, china. a Qualitative study. http://doi.org/10.1002/j.2161-0045 visited 01/06/18.

[25] Lusk, S. L. \&Fazzaro, D. (2006). Effects of psychological factors on careers and workforce development of students with disabilities. Journal of Employment and Counseling.

[26] Munyingi, L. (2012). Factors affecting career choices of female students in the Kenyan tertiary institutions: a case of us of international university (USIU-Africa). Kenya: University of Nairobi.

[27] Nord, D. (2012). People with disabilities in America's work force: time for fresh thinking. Impact, vol, $25,1$.

[28] Olaosebikan, O. I. \&Olusakin, A. (2014). Effects of parental influence on adolescent's career choice in Baldagry Local Government area of Lagos state, Nigeria. Journal of Research and Methods in Education. Vol 4, 44-57.

[29] Pappas, S. T. \&Kounenou, K. (2011). Career decision making of Greek post-secondary vocational students: The impact of parents and career decision making efficacy. Procedia Social and Behavoural Sciences, 15, 3410-3414.

[30] Rafiq, W. M. H., Fatima, T., Sohail, M. M., Saleem, M. \& Khan, A. M. (2013). Parental involvement and academic achievement: A study on secondary students. Lahore, Pakstan.

[31] Rani, S, D. (2014). Impact of parenting styles on career choices of adolescents. Journal of Education and Social Policy, Vol 1, (1), 19-22.

[32] Reinsk, D. (2011). What is ethics in research and why is it important? New York: Oxford University Press.

[33] Roundy, 1. (2015). Bronfenbrenner's ecological system. Www.Citethisformcom/Topic Visited August, 2017.

[34] Schultheiss, D. E. P., Kress, H. M., Manzi, A. J., \& Glasscock, M. J. (2001). Relational influences in career development: A qualitative inquiry. Counseling Psychologist, 29 (2), 214-239.

[35] Shonkorff, J.P. (2003). From neurons to neighbourhoods. The Science of early childhood. development. Www.Familyimpactserminars.Org/Org.Asp?D=Msfsoi Report Pdf.

[36] Tziner, A, Loberman, G., Dekel, Z. \&Sharoni, G. (2012). The influence of the parent offspring relationship on young peoples' career performance. Revista de psicologia del Trabayo y delas, Vol 28, (2), 99-105.

[37] Udoh, N. A. \&Sanni, K. B. (2012). Parental background variables and the career choice of secondary school students in Uyo local government area, Nigeria. Mediterranean. Journal of Social Sciences, 3, (1).

[38] Wahyuni, D., (2012). The research design maze: understanding paradigms, cases, methods and methodologies, Journal of Applied Management Accounting Research, Vol. 10, 1, 69-80.

[39] Zhao, X., Lim. V. M.\&Teo, T. S. (2012). The long arm of job insecurity: Its impact on career specific parenting behaviour and youths career self-efficacy. Journal of Vocational Behaviour 80, 619-218.

Citation: Mathatha Viola, Ndhlovu Daniel. "Influence of Parental Education on Career Development of Youths with Intellectual Disabilities in Selected Skills Training Institutions in Zambia" International Journal of Humanities Social Sciences and Education (IJHSSE), vol 5, no. 12, 2018, pp. 142-150. doi: http://dx.doi.org/10.20431/2349-0381.0512015.

Copyright: (C) 2018 Authors. This is an open-access article distributed under the terms of the Creative Commons Attribution License, which permits unrestricted use, distribution, and reproduction in any medium, provided the original author and source are credited. 